\title{
Pigtail Drain
}

National Cancer Institute

\section{Source}

National Cancer Institute. Pigtail Drain. NCI Thesaurus. Code C122612.

A hollow tube that has holes in the wall of the tube and a coiled tip and is inserted into a body cavity or organ to promote drainage. 